\title{
Arterial Mesenteric Thrombosis as a Complication of SARS-CoV-2 Infection
}

\author{
Lia a Beccara, Carlotta Pacioni, Sara Ponton, Simone Francavilla, Antonio Cuzzoli \\ Emergency Department, ASST di Cremona, Cremona, Italy
}

Doi: 10.12890/2020_001690 - European Journal of Case Reports in Internal Medicine - ๑ EFIM 2020

Received: $26 / 04 / 2020$

Accepted: $27 / 04 / 2020$

Published: $30 / 04 / 2020$

How to cite this article: a Beccara L, Pacioni C, Ponton S, Francavilla S, Cuzzoli A. Arterial mesenteric thrombosis as a complication fo SARS-CoV-2 infection. EJCRIM 2020;7: doi:10.12890/2020_001690.

Conflicts of Interests: The Authors declare that there are no competing interests.

This article is licensed under a Commons Attribution Non-Commercial 4.0 License

\section{ABSTRACT}

A 52-year-old patient with SARS-CoV-2 was diagnosed with interstitial pneumonia and treated with darunavir/ritonavir, hydroxychloroquine, azithromycin and low molecular weight heparin (LMWH). After LMWH cessation, he developed superior mesenteric arterial thrombosis. An abdominal CT scan showed arterial thrombosis of vessels efferent of the superior mesenteric artery with bowel distension.

COVID-19 may predispose to venous and arterial thromboembolism. Anticoagulation prophylaxis should be considered in hospitalized patients with COVID-19, and potential thromboembolism investigated in each symptomatic patient affected by SARS-CoV-2.

\section{LEARNING POINTS}

- Potential thromboembolism must be investigated in each symptomatic patient with SARS-CoV-2 infection.

- The preventive and therapeutic use of antithrombotic agents should be strongly considered in order to mitigate thrombotic and haemorrhagic events in patients with SARS-CoV-2 infection.

\section{KEYWORDS}

Mesenteric thrombosis, abdominal pain, COVID-19

\section{INTRODUCTION}

SARS-CoV-2 infection has spread rapidly throughout the world, causing millions of infections and nearly 200,000 deaths at the time of writing [1] and was declared a pandemic by the WHO on 11 March $2020{ }^{[2]}$. Autopsy examinations have demonstrated microcirculation damage and thrombosis with venous and arterial microembolism ${ }^{[3]}$. COVID-19 may predispose to both venous and arterial thromboembolism due to excessive inflammation, hypoxia, immobilization and diffuse intravascular coagulation ${ }^{[4,5]}$. No cases of arterial mesenteric embolism have been reported in the current literature.

We describe the case of a 52-year-old patient with SARS-CoV-2 who developed superior mesenteric arterial thrombosis.

\section{CASE DESCRIPTION}

A 52-year-old man was admitted to the emergency room of Cremona hospital on 27 March. He presented with a 10-day history of cough and fever but no other past illnesses. For the previous 3 days he had been treated with azithromycin 500 mg once a day and hydroxychloroquine 200 mg twice a day as prescribed by his general practitioner. A nasopharyngeal swab was obtained. Blood tests, arterial blood gas analysis and a thoracic CT scan were performed, demonstrating interstitial pneumonia and acute respiratory insufficiency, which was initially treated with oxygen. The nasopharyngeal swab tested positive for SARS-CoV-2.

The patient was admitted to our medical department with the diagnosis of interstitial pneumonia due to SARS-CoV-2. He started antiretroviral therapy with darunavir/ritonavir $800 / 100 \mathrm{mg}$ a day, hydroxychloroquine $200 \mathrm{mg}$ twice a day, azithromycin $500 \mathrm{mg}$ once a day and low molecular weight heparin $(\mathrm{LMWH}) 4,000 \mathrm{U}$ daily, according to hospital protocol. The patient improved clinically and was 
discharged from hospital on 4 April (after 7 days of hospitalization), without fever or cough and with a prescription for hydroxychloroquine twice a day until 7 April.

However, on 8 April, the patient complained of fever $\left(37.5^{\circ} \mathrm{C}\right)$, which was treated with paracetamol, and two episodes of diarrhoea and was admitted the next day to the emergency department for vomiting and abdominal pain. His blood pressure was 120/70 mmHg, oxygen saturation was $99 \%$ on room air, heart rate was $90 \mathrm{bpm}$, and temperature was $36.3^{\circ} \mathrm{C}$. The abdomen was soft, not distended, and painful to palpation in the epigastric-mesogastric region. Blood tests demonstrated a regular white cell count and C-reactive protein (CRP) of $44 \mathrm{mg} / \mathrm{dl}$ (lower than the previous value of $65 \mathrm{mg} / \mathrm{dl}$ at hospital discharge). An abdominal x-ray and ultrasound were performed, proving negative for abdominal disease. The patient started combination therapy with continuous infusion of omeprazole as a gastroprotectant and intravenous fentanest $100 \mu \mathrm{g}$ as a painkiller and was monitored in the emergency department.

He was still symptomatic 4 hours after fentanest administration and therefore underwent an abdominal contrast-enhanced CT scan, which resulted negative for abdominal effusion and demonstrated no vascular abnormalities. Gastroscopy was requested. During the night the patient's symptoms improved but the next morning he complained of fever, and his clinical conditions worsened without clinical signs of acute abdomen. Blood analysis showed leucocytosis (30,000 white blood cells) and CRP $222 \mathrm{mg} / \mathrm{dl}$. An urgent surgical consultation was requested and a new abdominal CT scan showed arterial thrombosis of vessels efferent of the superior mesenteric artery with bowel distension (Fig. 1). Surgical examination confirmed the intestinal ischaemia. An intestinal resection with stapled side-to side anastomosis was performed. The patient was discharged from hospital 10 days after surgery, with regular bowel function. He was instructed to continue LMWH plus aspirin $100 \mathrm{mg}$ per day.

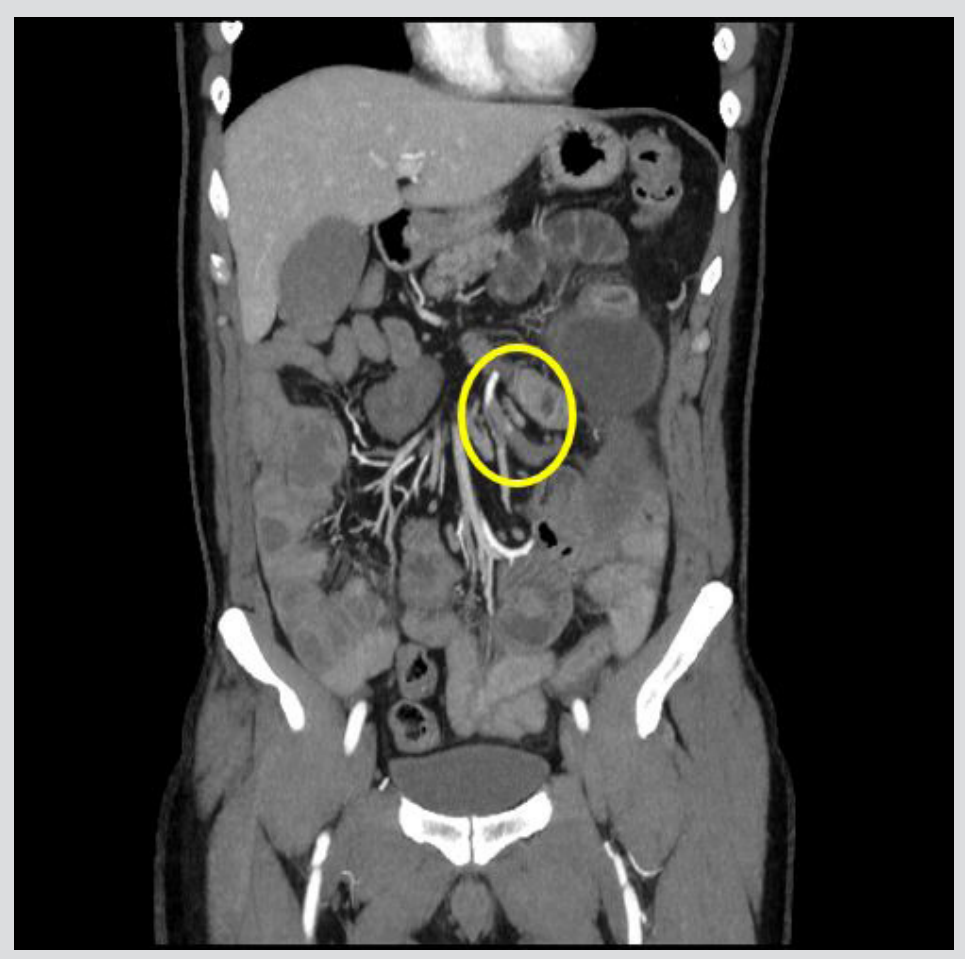

Figure 1. CT scan showing arterial thrombosis and bowel distension

\section{DISCUSSION}

Our patient was discharged from the medical department after 7 days of treatment with LMWH at a prophylactic dose, but developed mesenteric arterial thrombosis 5 days after cessation of heparin. This case supports the administration of anticoagulation prophylaxis in hospitalized patients with COVID-19 and the need to investigate potential thromboembolism in each symptomatic patient affected by SARS-CoV-2. 


\section{REFERENCES}

1. World Health Organization. Coronavirus Disease 2019 (COVID-19). Situation report - 98. Available from: https://www.who.int/docs/default-source/coronaviruse/situationreports/20200427-sitrep-98-covid-19.pdf?sfvrsn=90323472_4 (accessed 28 April 2020).

2. World Health Organization. WHO announces COVID-19 outbreak a pandemic. Available from: http://www.euro.who.int/en/health-topics/health-emergencies/coronaviruscovid-19/news/news/2020/3/who-announces-covid-19-outbreak-a-pandemic (accessed 27 April 2020).

3. Li H, Liu L, Zhang D, Xu J, Dai H, Tang N, et al. SARS-CoV-2 and viral sepsis: observations and hypotheses. Lancet 2020 Apr 17. pii: S0140-6736(20)30920-X. doi: 10.1016/ S0140-6736(20)30920-X [Epub ahead of print].

4. Bikdeli B, Madhavan MV, Jimenez D, Chuich T, Dreyfus I, Driggin E, et al. COVID-19 and thrombotic or thromboembolic disease: implications for prevention, antithrombotic therapy, and follow-up. J Am Coll Cardiol 2020 Apr 15. pii: S0735-1097(20)35008-7. doi: 10.1016/j.jacc.2020.04.031 [Epub ahead of print].

5. Klok FA, Kruip MJHA, van der Meer NJM, Arbous MS, Gommers DAMPJ, Kant KM, et al. Incidence of thrombotic complications in critically ill ICU patients with COVID-19. Thromb Res 2020 Apr 10. pii: S0049-3848(20)30120-1. doi: 10.1016/j.thromres.2020.04.013 [Epub ahead of print]. 